\title{
Direct Experimental Impulse Measurements for Detonations and Deflagrations
}

\author{
M. Cooper, ${ }^{*}$ S. Jackson, ${ }^{\dagger}$ J. Austin, ${ }^{\dagger}$ E. Wintenberger ${ }^{\dagger}$ and J. E. Shepherd ${ }^{\ddagger}$ \\ California Institute of Technology, Pasadena, California 91125
}

\begin{abstract}
Direct impulse measurements were carried out by using a ballistic pendulum arrangement for detonations and deflagrations in a tube closed at one end. Three tubes of different lengths and inner diameters were tested with stoichiometric propane- and ethylene-oxygen-nitrogen mixtures. Results were obtained as a function of initial pressure and percent diluent. The experimental results were compared to predictions from an analytical model and generally agreed to within $15 \%$ (Wintenberger, E., Austin, J., Cooper, M., Jackson, S., and Shepherd, J. E., "Analytical Model for the Impulse of a Single-Cycle Pulse Detonation Engine, AIAA Paper 2001-3811, July 2001). The effect of internal obstacles on the transition from deflagration to detonation was studied. Three different extensions were tested to investigate the effect of exit conditions on the ballistic impulse for stoichiometric ethylene-oxygen-nitrogen mixtures as a function of initial pressure and percent diluent.
\end{abstract}

\section{Nomenclature}

\section{$A=$ area}

$A_{\text {lip }}=$ area of lip at exit of tube

$A_{\mathrm{TS}}=$ area of thrust surface

$c_{2}=$ sound speed of burned gases just behind detonation wave

$c_{3}=$ sound speed of burned gases behind Taylor wave

$d=$ inner diameter of detonation tube

$F=$ force exerted on detonation tube in direction of tube axis

$g=$ standard Earth gravitational acceleration

$I=$ single-cycle impulse

$I_{\mathrm{sp}} \quad=$ mixture-based specific impulse

$I_{V}=$ impulse per unit volume

$L=$ length of detonation tube filled with charge

$L_{p}=$ length of pendulum arm

$L_{t}=$ overall length of detonation tube and extension

$m \quad$ = pendulum mass

$P=$ pressure

$P_{\text {env }}=$ environment pressure

$P_{\text {lip }}=$ pressure on lip at exit of tube

$P_{\mathrm{TS}}=$ pressure on thrust surface in detonation tube interior

$P_{1}=$ initial pressure of reactants

$P_{2}=$ Chapman-Jouguet pressure

$P_{3}=$ pressure of burned gases behind Taylor wave

$p=$ pitch of spiral obstacles

$S=$ wetted surface area of tube's inner diameter

$T_{1}=$ initial temperature of reactants

$t=$ time

$U_{\mathrm{CJ}}=$ Chapman-Jouguet detonation velocity

$V=$ internal volume of detonation tube

$\beta=$ ratio of $\mathrm{N}_{2}$-to- $\mathrm{O}_{2}$ concentration in initial mixture

$\gamma=$ ratio of specific heats in combustion products

$\Delta x=$ horizontal pendulum displacement

$\lambda=$ cell size

$\rho_{1}=$ density of combustible mixture at the initial temperature and pressure

$\tau=$ wall shear stress

Received 14 September 2001; revision received 14 June 2002; accepted for publication 17 June 2002. Copyright (C) 2002 by the American Institute of Aeronautics and Astronautics, Inc. All rights reserved. Copies of this paper may be made for personal or internal use, on condition that the copier pay the $\$ 10.00$ per-copy fee to the Copyright Clearance Center, Inc., 222 Rosewood Drive, Danvers, MA 01923; include the code 0748-4658/02 \$10.00 in correspondence with the CCC.

* Graduate Student, Graduate Aeronautical Laboratories, Mechanical Engineering.

Graduate Student, Graduate Aeronautical Laboratories, Aeronautics.

* Professor, Graduate Aeronautical Laboratories, Aeronautics.

\section{Introduction}

MPULSE per cycle is one of the key performance measures of a pulse detonation engine. To evaluate the performance of the engine concept, it is necessary to have reliable estimates of the maximum impulse that can be obtained from the detonation of a given fuel-oxidizer combination at a specified initial temperature and pressure. Although the overall performance of an engine will depend strongly on a number of other factors such as inlet losses, nonuniformity of the mixture in the detonation tube, and the details (nozzles, extensions, coflow, etc.) of the flow downstream of the detonation tube exit, conclusive studies investigating the impulse available from a simple detonation tube must be completed. Many researchershave measured the impulse created by detonating a uniform mixture in a constant-area tube that is closed at one end and open at the other with a variety of experimental techniques.

The pioneering work measuring impulse was in 1957 by Nicholls et al., ${ }^{1}$ who measured the specific impulse produced by a detonation tube using a ballistic pendulum technique. They measured the single-cycle specific impulse of acetylene- and hydrogenoxygen mixtures and carried out some multicycle experimentsusing hydrogen-air; however, their experimental values are significantly lower than modern data. ${ }^{2-4}$

Zitoun and Desbordes ${ }^{5}$ made an experimental determination of the impulse of a detonation tube using a stoichiometric ethyleneoxygen mixture by integrating the pressure history at the closed end of the tube. They performed their experiments for single-cycle and multicycle cases and observed a 30\% decreasein the level of impulse for multicycle experiments. They attributed this impulse deficit to inadequate filling of the detonation tube. Zhdan et al. ${ }^{4}$ measured the impulse generated by a stoichiometric acetylene-oxygen mixture in a short ( 0.125 or $0.25 \mathrm{~m}$ long) cylindrical detonation tube during single-cycle operation using a ballistic pendulum technique. The detonation tube was, in some cases, partially filled with air.

Schauer et al. ${ }^{2}$ used a damped thrust stand to measure the impulse of a multicycle pulse detonation tube operating with hydrogen-air and more recently, hydrocarbon-airmixtures. Harris et al. ${ }^{6}$ studied the effect of deflagration-to-detonation transition (DDT) distance on the impulse of a detonation tube using a ballistic pendulum technique with stoichiometric propane-oxygen mixtures diluted with nitrogen. They showed that there is no significant difference in impulse between directly initiated tests and DDT-initiated tests as long as DDT occurred in the tube and none of the combustible mixture was expelled from the tube before detonation.

The present study (preliminary results given by Cooper et al. ${ }^{3}$ ) reports single-cycle impulse measurements for ethylene- and propane-oxygen-nitrogen mixtures in three tubes with different lengths, inner diameters, and internal obstacles using a ballistic 
pendulum arrangement with varying initial pressure and diluent amount. In a companion paper, ${ }^{7}$ a simple model for impulse is developed and compared to both the present results and selected results from the experiment studies quoted earlier. This analytical model ${ }^{7}$ provides estimates for the impulse per unit volume and specific impulse of a single-cycle pulse detonation engine for a wide range of fuels (including aviation fuels) and initial conditions.

One of the original motivations of this experimental work was to provide a database useful for the validation of both numerical and analytic models. When our studies were initiated in 1999, there was substantialcontroversy over the impulse that could be obtained from an open-ended detonation tube. The present results, taken together with our simple model, ${ }^{7}$ numerical simulations, and experiments of others (reviewed by Kailasanath ${ }^{8}$ ), demonstrate that at least for some fuels (ethylene) there is reasonable agreement of the impulse that can be obtained from a simple detonation tube.

The paper is organized as follows. First, we discuss the experimental details including the setup and impulse measurement technique with its associated uncertainty analysis. Second, we present experimental results on different DDT regimes followed by singlecycle impulse values for tubes containing spiral obstacles, singlecycle impulse values for tubes containing orifice or blockage plate obstacles, and single-cycle impulse values for tubes with extensions. Third, we discuss the implications of these results for pulse detonation engine technology.

\section{Experimental Setup and Procedure}

The detonation tube of Fig. 1 consisted of a constant area tube closed at one end by the thrust surface containing the ignition source and open at the other end, but initially sealed with a $25-\mu$ m-thick Mylar ${ }^{\circledR}$ diaphragm. The tube was hung from the ceiling by four steel wires in a ballistic pendulum arrangement shown schematically in Fig. 2. Direct measurements were made of the impulse delivered by a DDT-initiated detonation or a flame by measuring the maximum horizontal displacement of the tube. The tube was evacuated to a pressure less than $13 \mathrm{~Pa}$ at the beginning of each experiment. When the method of partial pressures was used, the individual gases comprising the initial mixture were added to the tube and subsequently mixed for 5 min with a circulation pump to ensure mixture homogeneity. A spark plug and associated discharge system with $30 \mathrm{~mJ}$ of stored energy was used to ignite the combustible mixture at the tube's thrust surface. Combustion products were free to expand out from the open end of the tube into a large $\left(\simeq 50 \mathrm{~m}^{3}\right)$ blast-proof room. Pressure histories were measured at several locations along the tube length and at the thrust surface (Fig. 3). Two of the tubes

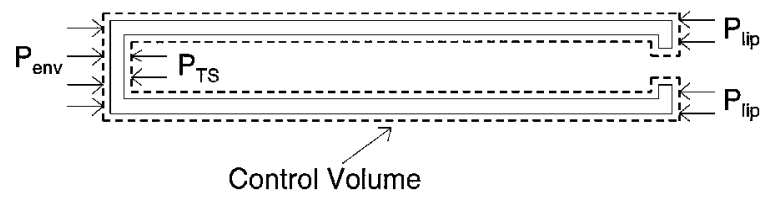

Fig. 1 Pulse detonation engine control volume. contained ionization gauges to measure the time of arrival of the flame or detonation front. The dimensions and diagonistic capabilities of the three detonation tubes tested are listed in Table 1.

The experimental variables included fuel type, initial pressure, diluent amount, and internal obstacles (Table 2). The internal obstacles included Shchelkin spirals, blockage plates, and orifice plates, all with a blockage ratio of 0.43 . The choice of blockage ratio, defined as the ratio of blocked area to the total area, was based on work by Lindstedt and Michels, ${ }^{9}$ who cite 0.44 as the optimal configuration. No effort was made in this research to study the effect of blockage ratio on DDT or impulse.

The Shchelkin spirals were constructed of stainless steel tubing, with a diameter necessary to yield a blockage ratio of 0.43 , coiled to fit inside the detonation tube (Fig. 4). The spiral's pitch $p$ refers to the axial distance between successive coils of the tubing. The spiral's length refers to the portion of the detonation tube length containing the spiral.

The blockage plate obstacles consisted of circular plates with an outer diameter smaller than the tube's inner diameter and of the size required to yield a blockage ratio of 0.43 (Fig. 5). The blockage plates were suspended along the centerline of the detonation tube by a single threaded rod and spaced approximately one tube diameter apart. Their length refers to the length of the detonation tube containing the blockage plate obstacles.

The orifice plate obstacles consisted of a ring with an outer diameter equal to the inner diameter of the detonation tube and an inner diameter of the size necessary to yield a blockage ratio of 0.43 (Fig. 6). The orifice plates were spaced approximately one

Table 1 Dimensions and diagnostic capabilities of tested detonation tubes

\begin{tabular}{lccc}
\hline \hline Length, $\mathrm{m}$ & Diameter, $\mathrm{mm}$ & Pressure transducers & Ion gauges \\
\hline 0.609 & 76.2 & 3 and 1 at thrust surface & 4 \\
1.016 & 76.2 & 3 and 1 at thrust surface & 10 \\
1.5 & 38.0 & 3 & 0 \\
\hline \hline
\end{tabular}

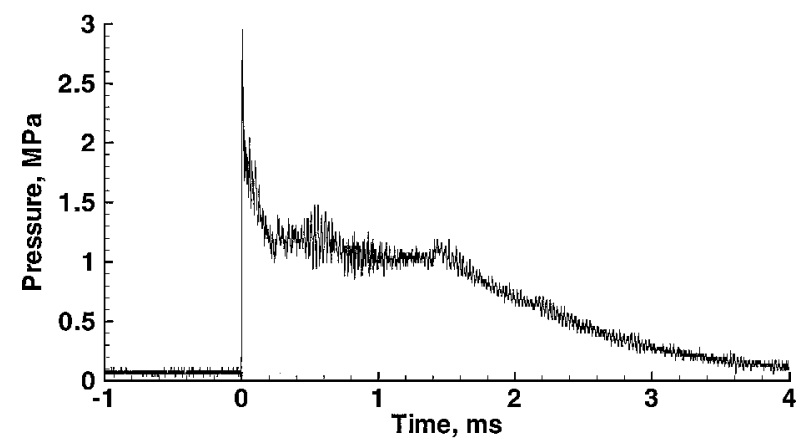

Fig. 3 Sample pressure trace of stoichiometric $\mathrm{C}_{2} \mathrm{H}_{4}-\mathrm{O}_{2}$ at $100-\mathrm{kPa}$ initial pressure recorded at the thrust surface.
Initial Position

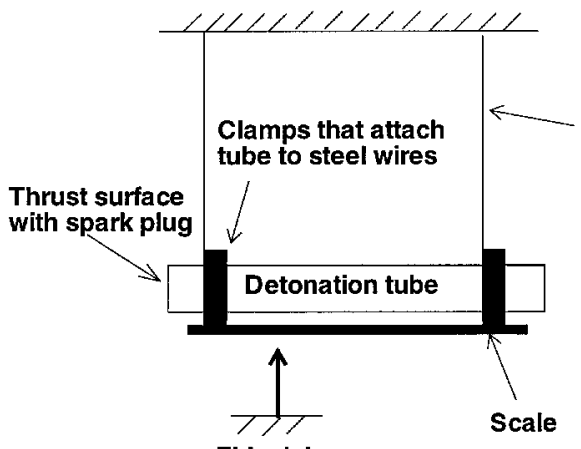

Fiducial
Fully deflected position

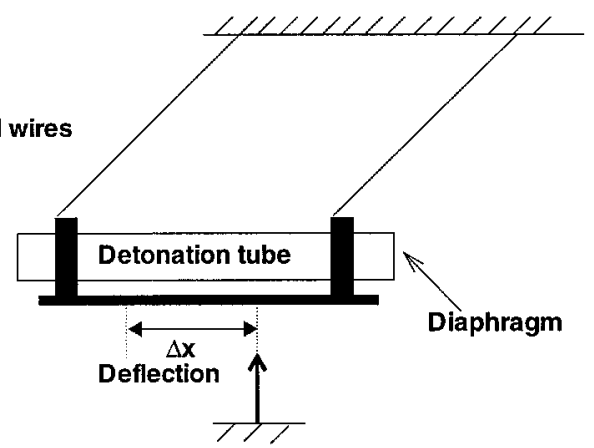

Fig. 2 Ballistic pendulum arrangement for direct impulse measurement. 
Table 2 Experimental variables of tested detonation tubes

\begin{tabular}{lcccl}
\hline \hline Length, $\mathrm{m}$ & Fuel tested & Pressure, kPa & Nitrogen, $\%$ & \multicolumn{1}{c}{ Internal obstacles } \\
\hline 0.609 & $\mathrm{C}_{3} \mathrm{H}_{8}$ & $50-100$ & 0-air & Spiral with length $=0.609 \mathrm{~m}, p=28 \mathrm{~mm}$ \\
0.609 & $\mathrm{C}_{3} \mathrm{H}_{8}$ & $50-100$ & 0-air & Spiral with length $=0.609 \mathrm{~m}, p=51 \mathrm{~mm}$ \\
1.016 & $\mathrm{C}_{2} \mathrm{H}_{4}$ & $30-100$ & 0-air & No obstacles \\
1.016 & $\mathrm{C}_{2} \mathrm{H}_{4}$ & $30-100$ & 0-air & Blockage plate with length $=1.016 \mathrm{~m}$ \\
1.016 & $\mathrm{C}_{2} \mathrm{H}_{4}$ & $30-100$ & 0-air & Orifice plate with length $=1.016 \mathrm{~m}$ \\
1.016 & $\mathrm{C}_{2} \mathrm{H}_{4}$ & $30-100$ & 0-air & Half orifice plate with length $=0.508 \mathrm{~m}$ \\
1.5 & $\mathrm{C}_{3} \mathrm{H}_{8}$ & $50-100$ & 0-air & Spiral with length $=0.305 \mathrm{~m}, p=11 \mathrm{~mm}$ \\
\hline \hline
\end{tabular}

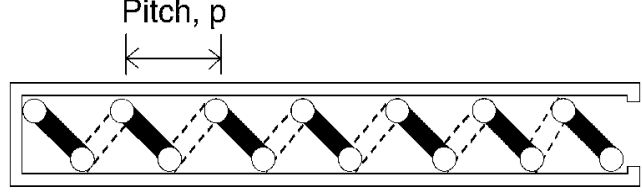

Fig. 4 Arrangement of spiral obstacles inside detonation tube.

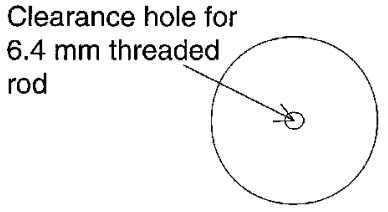

a)

6.4

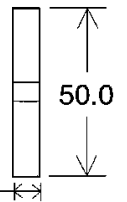

Supports ( 3 places)

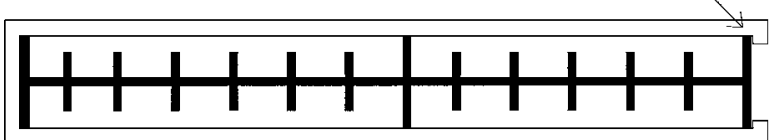

b)

Fig. 5 Blockage plate obstacles: a) dimensions of blockage plates in millimeters and b) arrangement of blockage plates inside detonation tube.

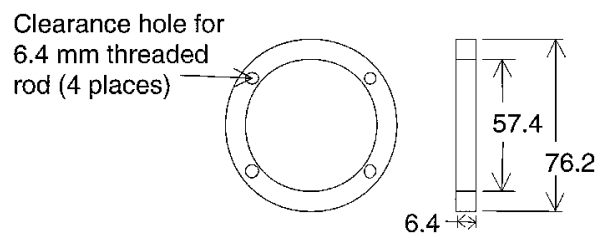

a)

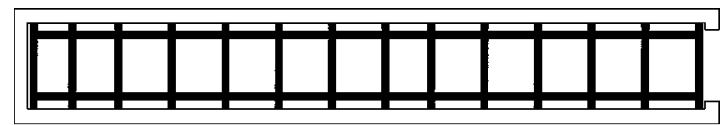

b)

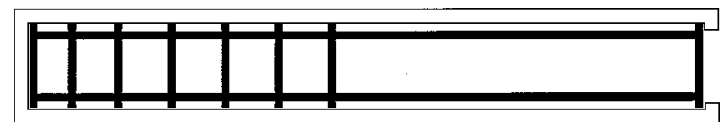

c)

Fig. 6 Orifice plate obstacles: a) dimensions of orifice plates in millimeters, b) arrangement of orifice plates inside detonation tube for the orifice plate configuration, and c) arrangement of orifice plates inside detonation tube for the half orifice plate configuration.

tube diameter apart. Their length refers to the length of the detonation tube containing the orifice plate obstacles as measured from the thrust surface. The orifice plate obstacles that fill half of the detonation tube are referred to as half orifice plate, whereas the orifice plate obstacles that fill the entire tube length are referred to as orifice plate.

Three extensions attached to the open end of the 1.016-m-length tube were tested, and a description of each appears in a later section.

\section{Impulse Measurement and Computation}

The impulse was determined by measuring the maximum horizontal deflection of the detonation tube, which is the oscillating mass of the ballistic pendulum. Each support wire was about $1.5 \mathrm{~m}$ in length so that the natural period of oscillation was about $2.45 \mathrm{~s}$. During free oscillations, the maximum horizontal deflection occurs at a time equal to one-quarter of the period or $610 \mathrm{~ms}$. The time over which the force is applied can be estimated ${ }^{7}$ as $10 t_{1}$, where $t_{1}=L / U_{\mathrm{CJ}}$ is the time required for the detonation to propagate the length of the tube. For the longest tube tested, the time over which the force is applied is approximately $7.5 \mathrm{~ms}$, which is significantly less than one-quarter of the oscillation period. Therefore, the classical analysis of an impulsively created motion can be applied, and the conservation of energy can be used to relate the maximum horizontal deflection to the initial velocity of the pendulum. From elementary mechanics, the impulse is given by

$$
I=m \sqrt{2 g L_{p}\left[1-\sqrt{1-\left(\Delta x / L_{p}\right)^{2}}\right]}
$$

This expression is exact given the assumptions discussed earlier and there are no limits on the values of $\Delta x$. Actual values of $\Delta x$ observed in our experiments were between 2 and $292 \mathrm{~mm}$. The impulse $I$ measured in this fashion is referred to as the ballistic impulse and is specific to a given tube size. Two measures of the impulse that are independent of tube size are the impulse per unit volume,

$$
I_{V}=I / V
$$

and the specific impulse based on the total explosive mixture mass,

$$
I_{\mathrm{sp}}=I / g \rho_{1} V
$$

The impulse can also be calculated by placing a control volume around the detonation tube and considering the conservation of momentum. The conventional control volume used in rocket motor analysis is not suitable because the exit flow is unsteady and the required quantities (exit pressure and velocity) are unknown. It is more useful to place the control volume on the surface of the detonation tube (Fig. 1) and write a force balance equation in the direction of the tube axis:

$$
\begin{aligned}
F= & \left(P_{\text {env }}-P_{\mathrm{ts}}\right) A_{\mathrm{ts}}+\sum_{\text {obstacles }} \int P \boldsymbol{n} \cdot \boldsymbol{x} \mathrm{d} A \\
& +\int \tau \mathrm{d} S+\left(P_{\text {env }}-P_{\text {lip }}\right) A_{\text {lip }}
\end{aligned}
$$

The first term on the right side of the equation is the force on the thrust surface, the second term is the drag (due to pressure differentials) over the obstacles, the third term is the viscous drag, and the last term represents the force over the tube wall thickness. The effect of heat transfer from the combustion products to the added surface area of the obstacles could also reduce the impulse due to a reduction of pressure internal to the detonation tube. We have not considered the role of heat transfer in the present investigation because our tubes are relatively short and the residence time is modest. We expect that heat transfer will become a significant issue for long tubes and/or tubes with exit restrictions that have long residence times for the hot products. 
The impulse is obtained by integrating this force over a cycle,

$$
I=\int F \mathrm{~d} t
$$

If all of the terms making up $F$ can be computed or measured, the ballisticimpulse and the impulse computed from this control volume integration should be identical. Previous studies ${ }^{5}$ have used Eq. (4) to analyze data from unobstructed tubes neglecting all but the first contribution to the force. This is a resonable approximation when fast transition to detonationoccurs; however, in the case of obstacles, the net contribution of the two drag terms may be substantial, and using the first term alone can result ${ }^{10}$ in overestimating the force and impulse by up to $50 \%$. Because it is difficult to estimate or measure accurately all of the terms in Eq. (4), direct measurement of the impulse is the only practical method for tubes with obstructions or other unusual features such as exit nozzles.

\section{Experimental Uncertainties}

An analysis was performed to quantify experimental uncertainties associated with the experimental setup and initial conditions using the standard method ${ }^{11}$ for estimating error propagation. Generally, the variance $\Delta I_{V}$ associated with the measured quantity $I_{V}\left(x_{1}, \ldots, x_{n}\right)$ can be estimated as

$$
\Delta I_{V}=\sqrt{\left(\frac{\partial I_{V}}{\partial x_{1}}\right)^{2}\left(\Delta x_{1}\right)^{2}+\cdots\left(\frac{\partial I_{V}}{\partial x_{n}}\right)^{2}\left(\Delta x_{n}\right)^{2}}
$$

Using the expression for ballistic impulse in Eq. (1), the uncertainty in the direct experimental measurements of the impulse per unit volume can be quantified. The estimated uncertainties in the pendulum arm length, measured pendulum deflection, pendulum mass, and the tube volume are given in Table 3. From this analysis, the total uncertainty in the direct impulse measurements due to the experimental setup was calculated to be at most $4 \%$.

Uncertainties in the initial conditions were also quantified. The measured leak rate was $50 \mathrm{~Pa} / \mathrm{min}$ from an initial pressure of $13 \mathrm{~Pa}$. The maximum time required to complete the experiment was $15 \mathrm{~min}$, which results in a worst-case air contamination of $810 \mathrm{~Pa}$. A study to identify the mixture most affected by this leak rate found stoichiometric ethylene-oxygen at an initial pressure of $30 \mathrm{kPa}$ and initial temperature of $295 \mathrm{~K}$ to be the most sensitive case. An error analysis was then performed for this mixture to find the maximum uncertainty in initial conditions for all experiments. The analytical model $^{7}$ can be used to express $I_{V}$ as a function of $U_{\mathrm{CJ}}, P_{3}$, and $c_{3}$. The quantity $\Delta U_{\mathrm{CJ}}$ is the difference in the Chapman-Jouguet velocity for a mixture containing an additional $810 \mathrm{~Pa}$ of air as a result of the leak and the ideal case. STANJAN ${ }^{12}$ was used to calculate $U_{\mathrm{CJ}}$ in each case. $\Delta P_{3}$ and $\Delta c_{3}$ can then be found from differences in $P_{3}$ and $c_{3}$ for the two mixtures, where $P_{3}$ and $c_{3}$ are given by the following relationships, which are derived by using the method of characteristics to relate flow properties on either side of the Taylor wave (see Ref. 7):

$$
\begin{gathered}
P_{3} / P_{2}=\left(c_{3} / c_{2}\right)^{2 \gamma /(\gamma-1)}=\{(\gamma+1) / 2 \\
\left.-[(\gamma-1) / 2]\left(U_{\mathrm{CJ}} / c_{2}\right)\right\}^{2 \gamma /(\gamma-1)}
\end{gathered}
$$

Table 4 lists the calculatedmaximum changes in the flow parameters due to the leak rate. Also shown are the largest possiblecontributions due to uncertainty in the initial pressure because of gauge precision

Table 3 Uncertainties used in determining the error for experimentally measured impulse

\begin{tabular}{lcc}
\hline \hline Quantity & Range of values & Uncertainty \\
\hline$L_{p}, \mathrm{~m}$ & $1.4-1.55$ & \pm 0.0016 \\
$\Delta x, \mathrm{~mm}$ & $2-292$ & \pm 0.5 \\
$m, \mathrm{~kg}$ & $12.808-55.483$ & \pm 0.001 \\
$V, \mathrm{~m}^{3}$ & $1.14-4.58 \times 10^{-3}$ & $\pm 4.5 \times 10^{-8}$ \\
\hline \hline
\end{tabular}

Table 4 Variations in flow parameters resulting from uncertainty in initial conditions due to error in dilution (leak rate), initial pressure, and initial temperature ${ }^{\mathrm{a}}$

\begin{tabular}{lcccc}
\hline \hline Parameter & Ideal & Dilution & Pressure & Temperature \\
\hline$P_{1}, \mathrm{kPa}$ & 30.0 & 30.0 & 30.1 & 30.0 \\
$T_{1}, \mathrm{~K}$ & 295 & 295 & 295 & 298 \\
$U_{\mathrm{CJ}}, \mathrm{m} / \mathrm{s}$ & 2317.9 & 2301.3 & 2307.5 & 2317.3 \\
$P_{2}, \mathrm{kPa}$ & 970.2 & 955.2 & 965.4 & 960.0 \\
$c_{2}, \mathrm{~m} / \mathrm{s}$ & 1249 & 1240 & 1243 & 1249 \\
$\gamma$ & 1.23 & 1.23 & 1.23 & 1.23 \\
$P_{3}, \mathrm{kPa}$ & 318.5 & 314.8 & 317.2 & 315.3 \\
$c_{3}, \mathrm{~m} / \mathrm{s}$ & 1123 & 1117 & 1119 & 1123 \\
$\Delta U_{\mathrm{CJ}}, \mathrm{m} / \mathrm{s}$ & - & 16.6 & 10.4 & 0.6 \\
$\Delta P_{3}, \mathrm{~Pa}$ & - & 3620 & 1242 & 3185 \\
$\Delta c_{3}, \mathrm{~m} / \mathrm{s}$ & - & 6.2 & 4.6 & 0.040 \\
$\Delta I_{V}, \% \mathrm{~b}$ & - & 1.7 & 0.6 & 1.5 \\
\hline \hline
\end{tabular}

${ }^{\mathrm{a}}$ Mixture is stoichiometric $\mathrm{C}_{2} \mathrm{H}_{4}-\mathrm{O}_{2}$ at initial pressure $30 \mathrm{kPa}$, which corresponds to the worst case of all mixtures considered in experiments.

${ }^{\mathrm{b}}$ Based on the model-predicted impulse.?

$( \pm 0.1 \mathrm{kPa})$ and due to uncertainty in the initial temperature $(295-$ $298 \mathrm{~K})$. All uncertainties shown are calculated for comparison with the same ideal case specified earlier.

When the results in Table 4 are combined, the uncertainty in the impulse measurement due to the initial conditions is found to contribute at most $\pm 2.3 \%$, which results in an overall maximum uncertainty of $\pm 6.3 \%$ in ballistic measurements of the impulse.

Experimental repeatability was also considered. For experiments in which fast transition to detonation occurred, the impulse was repeatable to within $\pm 0.7 \%$. In cases where late DDT or fast flames were observed, the impulse in repeat experiments varied by as much as $\pm 17 \%$ due to the turbulent nature of the flow during the initiation process. Additional experiments were conducted to verify that no out-of-plane motion existed during the initial pendulum swing.

The mass of the diaphragm was $0.27 \mathrm{~g}$. For comparison, the mass of the ethylene-air mixture at $50 \mathrm{kPa}$ (one of the lighter mixtures) is $3.3 \mathrm{~g}$. Because the mass of the diaphragmis $8 \%$ of the total explosive mixture mass, we expect that in the worst case this would have a tamping effect equivalent to adding an inert gas-filled extension that is $8 \%$ of the original tube length. We estimate ${ }^{13}$ that this would have the effect of slightly (1-2\%) increasing the impulse over the ideal (zero mass diaphragm) case. However, because the diaphragm is located at the end of the tube, the movement of the diaphragm away from the tube exit following the arrival of the detonation is expected to diminish rapidly the tamping effect.

Uncertainty in the DDT times was determined using the distance between two successive ionization probes and the ChapmanJouguet velocity calculated with STANJAN ${ }^{12}$ for each of the initial mixtures. In the experiments, transition to detonation was marked by a measured wave velocity greater than the calculated ChapmanJouguet velocity followed by a relaxation to the expected detonation velocity. Thus, dividing the distance between two successive ionization gauges by the calculated detonation velocity (instead of the overdriven detonation velocity observed at the transition) results in an upper bound on the uncertainty of $\pm 46.4 \mu \mathrm{s}$.

\section{Experimental Results}

\section{Detonation Initiation Regimes}

As stated in the experimental setup, all mixtures were ignited by a spark with a discharge energy $(30 \mathrm{~mJ})$ less than the critical energy required for direct initiation of a detonation (approximately $283 \mathrm{~kJ}$ for propane-air mixtures ${ }^{14}$ and approximately $56 \mathrm{~kJ}$ for ethyleneair mixtures ${ }^{14}$ at atmospheric conditions). Thus, detonations were obtained only by transition from an initial deflagration. The presence of a deflagration is denoted by a gradual rise in the pressure histories as the unburned gas ahead of the flame is compressed due to the expansion of the burned gases behind the flame. If the correct conditions exist, this initial deflagration can transition to a detonation wave. Otherwise, transition will not occur and the deflagration wave will travel the entire length of the tube. An abrupt pressure 

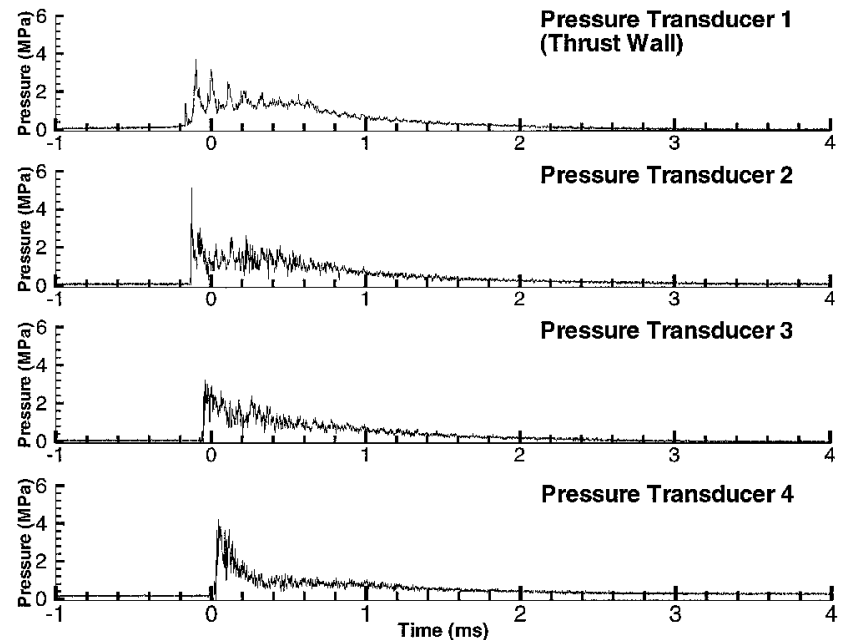

Fig. 7 Pressure history recorded for a stoichiometric $\mathrm{C}_{3} \mathrm{H}_{8}-\mathrm{O}_{2}$ mixture at $100-\mathrm{kPa}$ initial pressure in $0.609-\mathrm{m}$-long tube illustrating fast transition to detonation case.
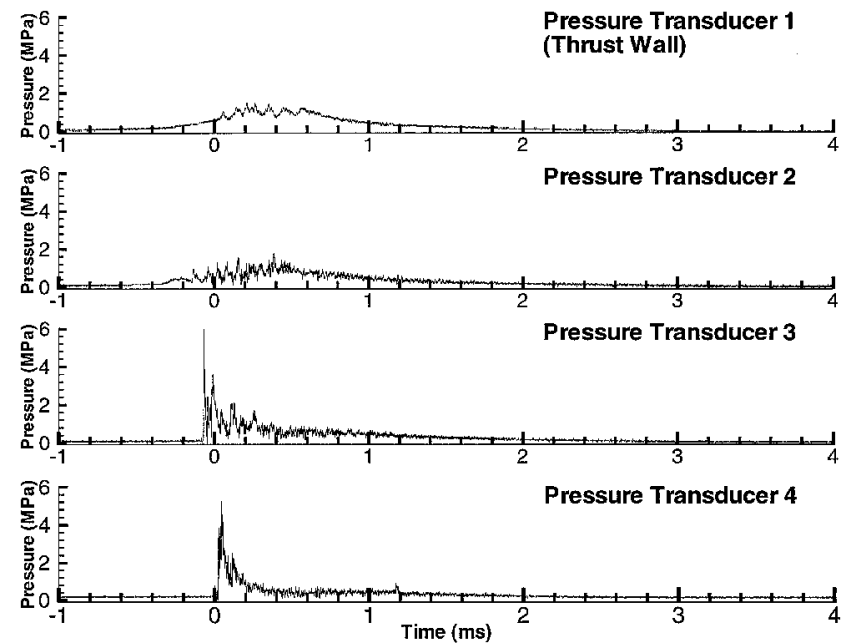

Fig. 8 Pressure history recorded for a stoichiometric $\mathrm{C}_{3} \mathrm{H}_{8}-\mathrm{O}_{2}-\mathrm{N}_{2}$ mixture with $\beta=1.5$ at $100-\mathrm{kPa}$ initial pressure in $0.609-\mathrm{m}$-long tube illustrating slow transition to detonation case.

jump ( $\Delta P>2 \mathrm{MPa}$ for hydrocarbonfuels $)$ is indicative of this transition, which can be quantified in terms of both the DDT time (from spark firing) and the DDT distance (axial distance from ignition source location) required for the event to occur.

Through multiple experiments with varying mixtures and internal obstacles, pressure histories and ionization gauges data were used to identify several combustion regimes including the DDT process. The pressure transducers were protected by a layer of thermally insulating vacuum grease. Although this delays the onset of heating of the gauge surface, our experience is that eventually thermal artifacts will be produced in the signal. Although we have not quantified this for the present experiments, the pressure signals are reproducible and physically reasonable.

These different combustion regimes are categorized as fast transition to detonation (Fig. 7), slow transition to detonation (Fig. 8), fast flames (Fig. 9), and slow flames (Fig. 10). Figure 7 illustrates the case of a fast transition to detonation, defined by an abrupt pressure increase before the first pressure transducer along the tube axis and the low DDT time. Figure 8 illustrates a slow transition to detonation case. An accelerating flame produces a gradual increase in pressure with time at the first and second pressure transducers, and transition to a detonation occurs between the second and third pressure transducers. In this case, the transition occurs late in the tube resulting in a longer DDT time. Figure 9 illustrates the case of a fast flame. The flame speed is fast enough to create significant compres-
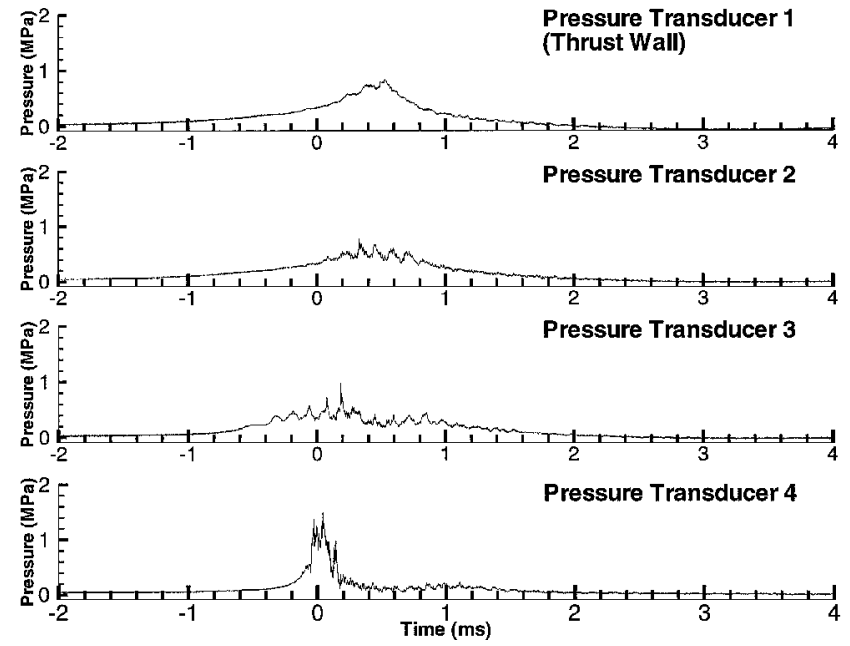

Fig. 9 Pressure history recorded for a stoichiometric $\mathrm{C}_{3} \mathrm{H}_{8}-\mathrm{O}_{2}-\mathrm{N}_{2}$ mixture with $\beta=3$ at $100-\mathrm{kPa}$ initial pressure in the $0.609-\mathrm{m}$-long tube illustrating fast flame case.
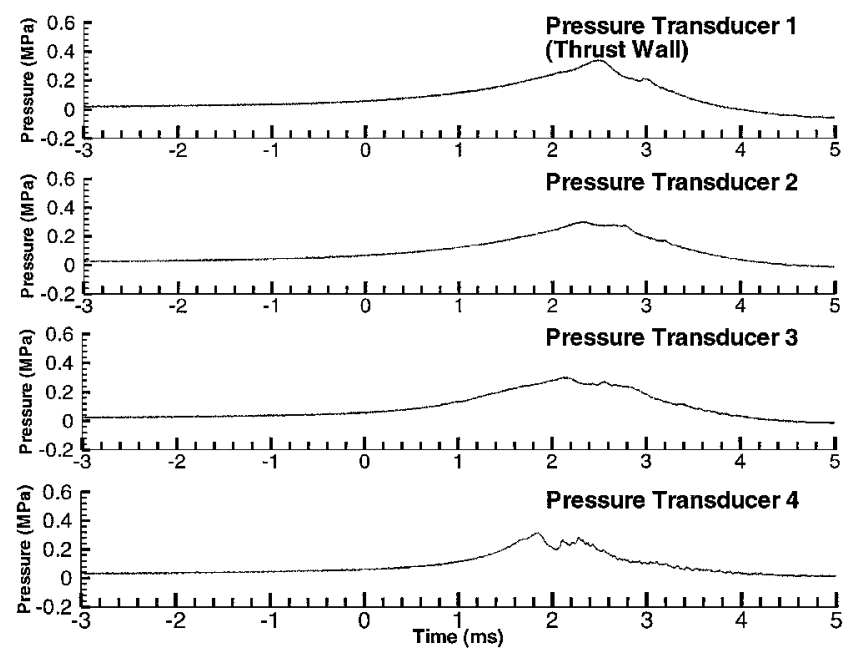

Fig. 10 Pressure history recorded for a stoichiometric $\mathrm{C}_{3} \mathrm{H}_{8}$-air mixture at $100-\mathrm{kPa}$ initial pressure in the $0.609-\mathrm{m}$-long tube illustrating slow flame case.

sion waves, but transition to detonation does not occur. Figure 10 illustrates the case of a slow flame. The flame speed is low, and only smooth pressure waves of low amplitude $(<0.5 \mathrm{MPa})$ are generated.

For cases when transition to detonation did occur, the DDT time was determined by measuring the combustion wave velocity and comparing this to the Chapman-Jouguet detonation velocity $U_{\mathrm{CJ}}$. The combustion wave velocity was estimated as the ratio of the distance between ionization probes to the time it took the reaction zone to pass from one ionization probe to the next. Transition is said to have occurred when this average combustion wave velocity is equal to or greater than the Chapman-Jouguet detonation velocity. The relative ability of the mixture to transition to detonation can be related to ${ }^{15,16}$ mixture properties such as the detonation cell size, expansion ratio, and deflagration speed. Necessary conditions for DDT are that the cell width be smaller than a specified fraction of the tube or obstacle dimensions, the expansion ratio (ratio of burned to unburned gas volume) must be larger than a minimum value, and the deflagration speed exceeds a minimum threshold. For cases of a straight tube, transition to detonation is possible only if the detonation cell width is smaller than the tube diameter (unobstructed tube) or smaller than the obstacles' aperture (obstructed tube).

Figures 11 and 12 plot the DDT time for ethylene-oxygennitrogen mixtures in the 1.016-m-longtube as a function of the initial pressure and diluent amount. Transition to detonation occurred in an unobstructed tube for mixtures at an initial pressure between 


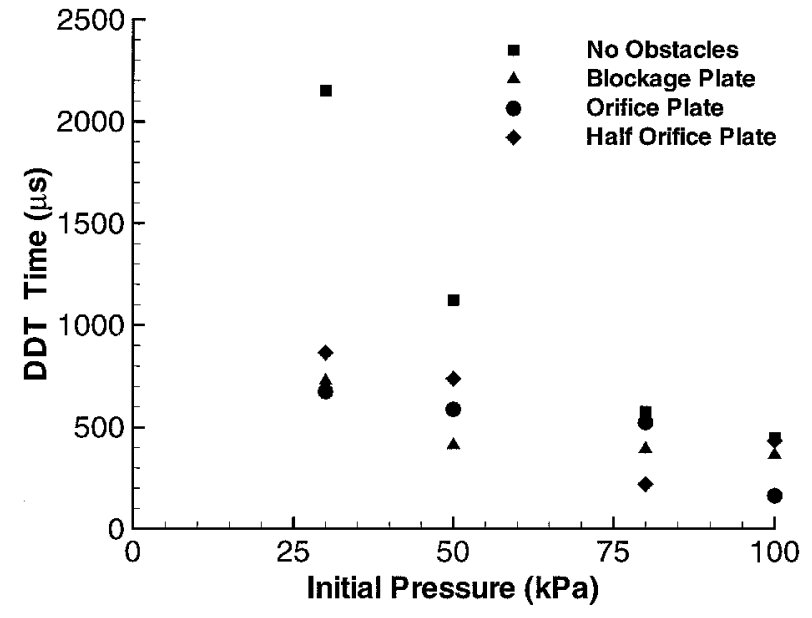

Fig. 11 Measured DDT time for stoichiometric $\mathrm{C}_{2} \mathrm{H}_{4}-\mathrm{O}_{2}$ mixtures with varying initial pressure for three obstacle configurations in the 1.016-m-long tube.

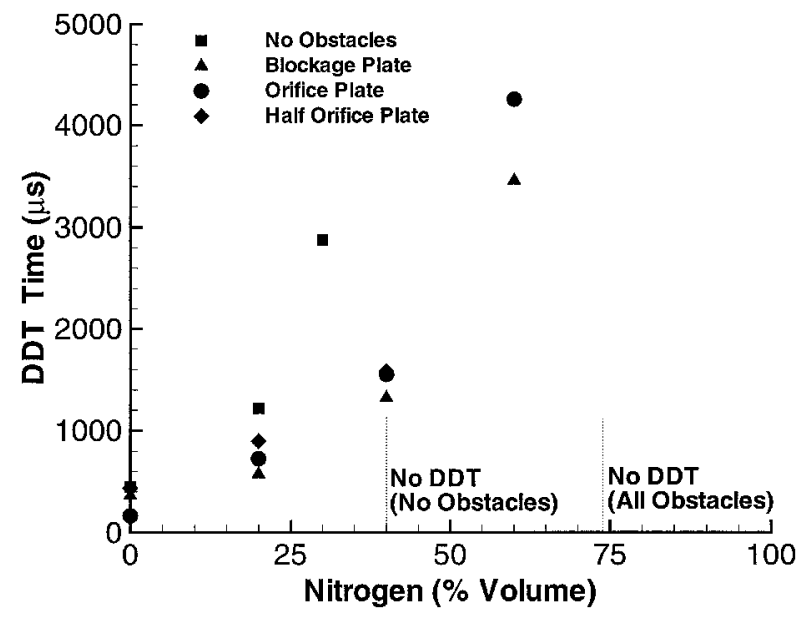

Fig. 12 Measured DDT time for stoichiometric $\mathrm{C}_{2} \mathrm{H}_{4}-\mathrm{O}_{2}$ mixtures with varying nitrogen dilution at $100-\mathrm{kPa}$ initial pressure for three obstacle configurations in 1.016-m-long tube.

30 and $100 \mathrm{kPa}$ and for mixtures up to $30 \%$ nitrogen. Because cell size increases with decreasing initial pressure and increasing dilution, the largest cell size was about $0.5 \mathrm{~mm}$ (Ref. 14) corresponding to ethylene-oxygen at $30 \mathrm{kPa}$ and about $0.6 \mathrm{~mm}$ (Ref. 14) corresponding to ethylene-oxygen-nitrogen at $30 \%$ dilution. For these two cases, the inclusion of obstacles reduced the DDT time by an average of $65 \%$. Additionally, the obstacles allowed DDT to occur in mixtures composed of up to $60 \%$ nitrogen (Fig. 12), corresponding to an approximate cell size of $10 \mathrm{~mm}$ (Ref. 14), as compared with DDT being achieved only up to $30 \%$ nitrogen in a tube with no obstacles. Thus, the presence of obstacles enabled mixtures with more diluent (less sensitive mixtures with a larger cell size) to transition to detonation, but there are limits to obstacle effectiveness. This is illustrated by the ethylene-air (74\% nitrogen dilution) mixture with an approximate cell size of $29 \mathrm{~mm}$ (Ref. 14), which did not transition to a detonation. Wintenberger et al. ${ }^{7}$ have used the ideas of Dorofeev et al. ${ }^{15}$ to estimate limits for DDT in obstructed tubes that are consistent with our observations.

\section{Impulse Measurements}

The following two sectionspresent single-cycleimpulse measurements with internal obstacles. To facilitate comparison between the different tube sizes, the results are given in terms of impulse normalized by the tube volume $I_{V}$, as well as the mixture-based specific impulse $I_{\text {sp }}$. Also shown an predicted impulse values from a model $^{7}$ that is based on analysis of the gas dynamic processes in the tube. The model impulse values are generally within $15 \%$ of the experimental impulse values over the range of pressures and diluent

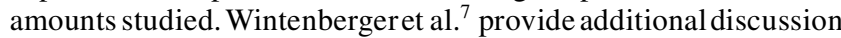
of differences between the experimental and model impulse values. As seen in both the measured and model data, ${ }^{7}$ the impulse per unit volume increases linearly with increasing initial pressure while the specific impulse tends to a constant value. The measured and model data $^{7}$ also show that both the impulse per unit volume and specific impulse decrease with increasing nitrogen dilution. This is due to the reduced amount of fuel present in a given volume of mixture with increasing amounts of dilution, which reduces the total energy released during combustion.

\section{Experiments with Spiral Obstacles}

Directimpulse measurementsfor propane-oxygen-nitrogen mixtures were made in two tubes of lengths of $0.609 \mathrm{~m}$ and $1.5 \mathrm{~m}$ with different Shchelkin spiral configurations. Figure 13 shows impulse as a function of initial pressure for both tubes, and Fig. 14 shows impulse as a function of diluent amount for the 0.609-m tube only.

From Fig. 13, it can be seen that the obstacles with a smaller pitch cause a greater reduction in impulse than those with a larger pitch. We attribute this loss in impulse as being due to a greater form drag associated with the flow around the obstacles as the spiral pitch decreases. At $100 \mathrm{kPa}$, a $5 \%$ reduction in the distance between successive coils causes a $13 \%$ reduction in impulse if the spirals extend over the entire tube length.

If DDT does not occur, the impulse is reduced (Fig. 14). DDT limits were discussed in the preceding section, but now the effect of late or no DDT on impulse can be investigated. As the mixture sensitivity decreases with increasing dilution, it becomes progressively more difficult to initiate a detonation within the tube. For large amounts of diluent, DDT does not occur within the tube, and only deflagrations are observed(Figs. 9 and 10). Deflagrations propagate down the tube at a relatively slower flame speed compressing the unburned gas ahead of the flame. This unburned gas compression is

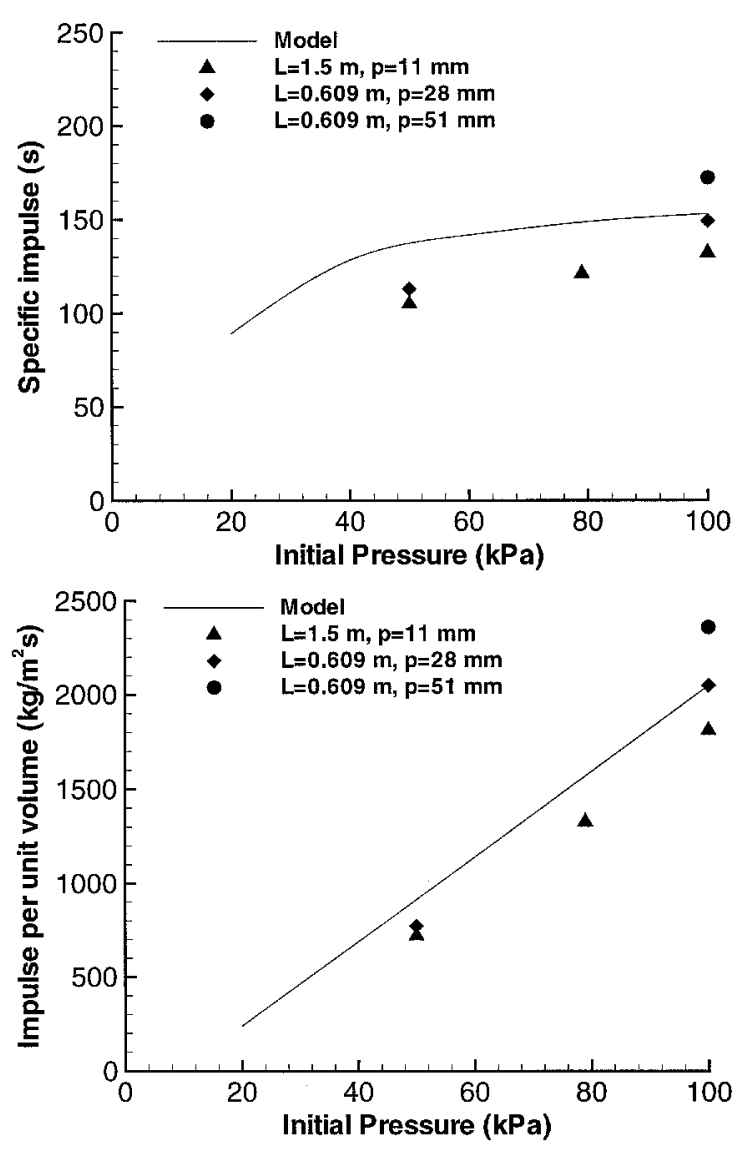

Fig. 13 Impulse measurements for stoichiometric $\mathrm{C}_{3} \mathrm{H}_{8}-\mathrm{O}_{2}$ mixtures with varying initial pressure in the $1.5-\mathrm{m}$ and $0.609-\mathrm{m}$-long tubes. 

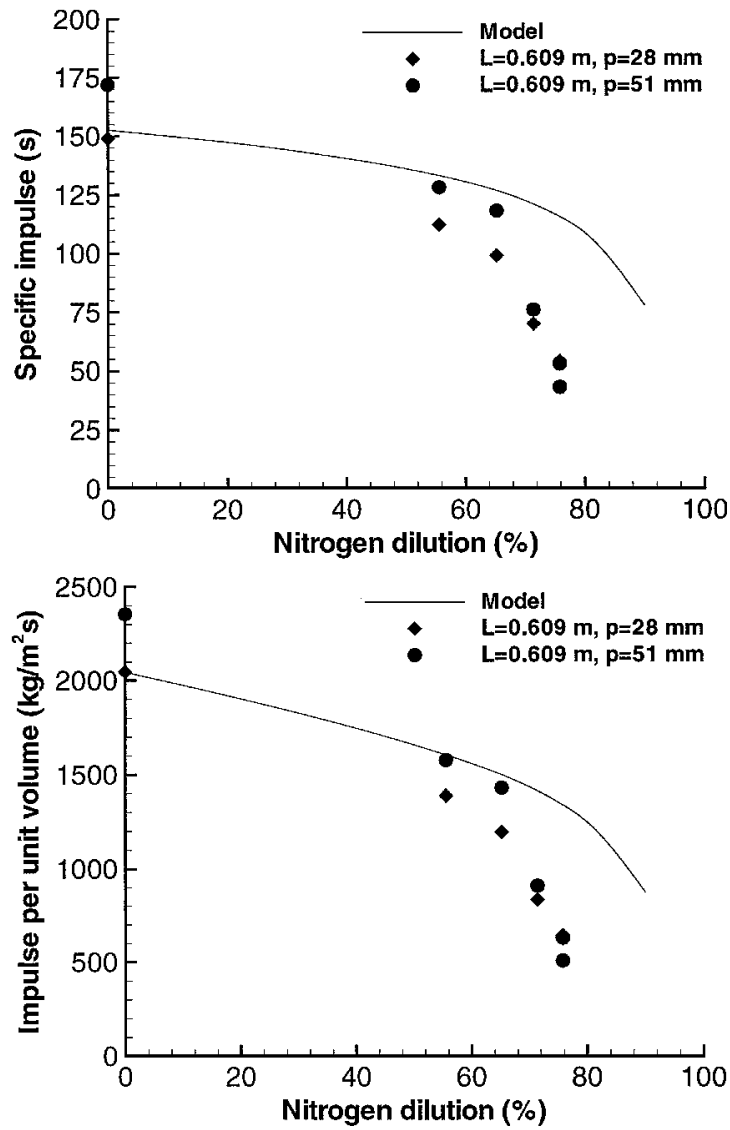

Fig. 14 Impulse measurements for stoichiometric $\mathrm{C}_{3} \mathrm{H}_{8}-\mathrm{O}_{2}$ mixtures with varying nitrogen dilution at $100-\mathrm{kPa}$ initial pressure in 0.609-m-long tube.

sufficient to rupture the thin diaphragm causing a considerable part of the mixture to be ejected outside the tube. Observations made by Jones and Thomas ${ }^{17}$ clearly demonstrate the gas motion and compression waves ahead of the flame. The mixture ejected from the tube does not contribute to the impulse due to its unconfined burning. The effect of this mixture spillage due to no DDT can be seen in the cases with greater than $70 \%$ diluent, where a $30-50 \%$ reduction in impulse is observed. The onset of a detonation wave can mitigate this effect due to its higher propagation speed. If DDT occurs early enough in the process, the detonation can overtake the compression waves created by the deflagration before they reach the diaphragm. The loss associated with this phenomenon is expected to become significant when DDT occurs in the last quarter of the tube, so that the detonation does not have time to catch up with the deflagration compression waves. Cases of late or no DDT illustrate the importance of more sophisticated initiation methods for less sensitive fuels, such as storable liquid hydrocarbons (Jet A, JP-8, JP-5, or JP-10) with cell widths similar to propane. Experiments with more sensitive ethylene-oxygen-nitrogen mixtures show that using obstacles to induce DDT within the tube can be effective.

\section{Experiments with Orifice and Blockage Plate Obstacles}

Impulse measurements for ethylene-oxygen mixtures in the 1.016-m-long tube appear in Fig. 15 as a function of initial pressure and Fig. 16 as a function of nitrogen dilution. Also shown are the analyticalmodel predictions? Without obstacles, detonation cannotbe achieved in this tube for nitrogen dilutions of $40 \%$ or greater. A dramatic drop in measured impulse results for these mixtures (Fig. 16). The addition of obstacles enabled DDT to occur in mixtures up to $60 \%$ nitrogen dilution. Beyond this point, the cell width is sufficiently large that transition to detonation occurs only in the latter portion of the tube and not all of the mixture burns within the tube.

Although obstacles can induce DDT in less sensitive mixtures and significantly increase the impulse, the obstacle drag can decrease
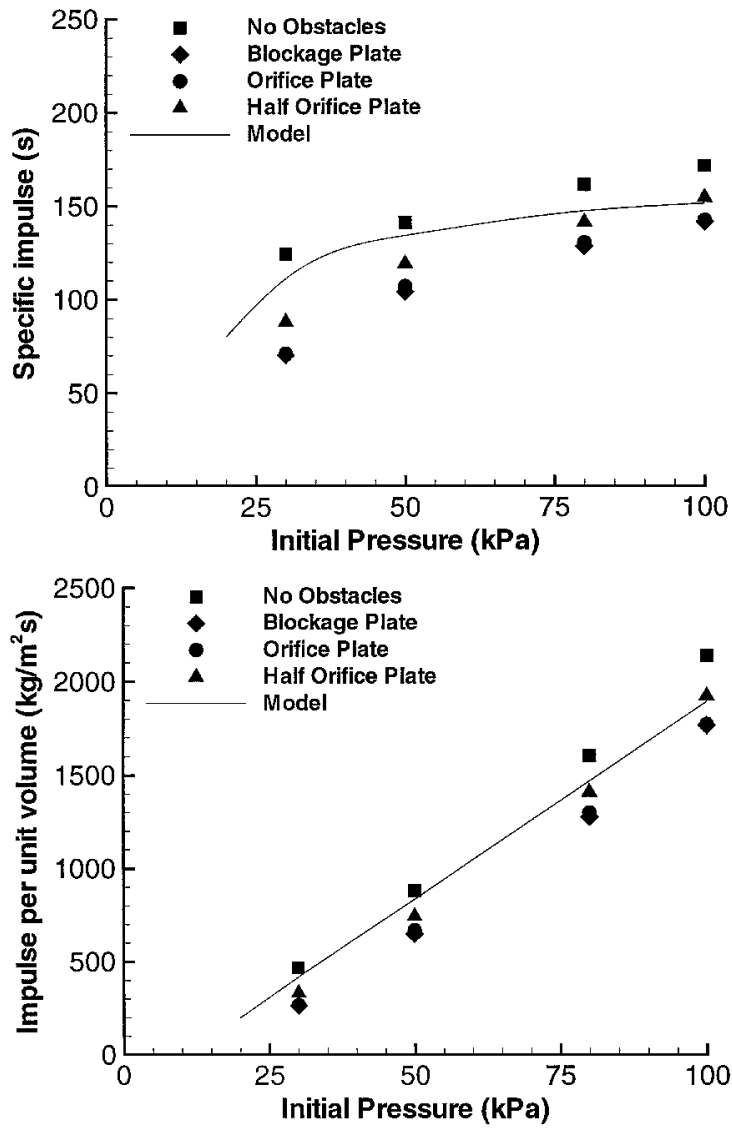

Fig. 15 Impulse measurements for stoichiometric $\mathrm{C}_{2} \mathrm{H}_{4}-\mathrm{O}_{2}$ mixtures with varying initial pressure in 1.016-m-long tube.
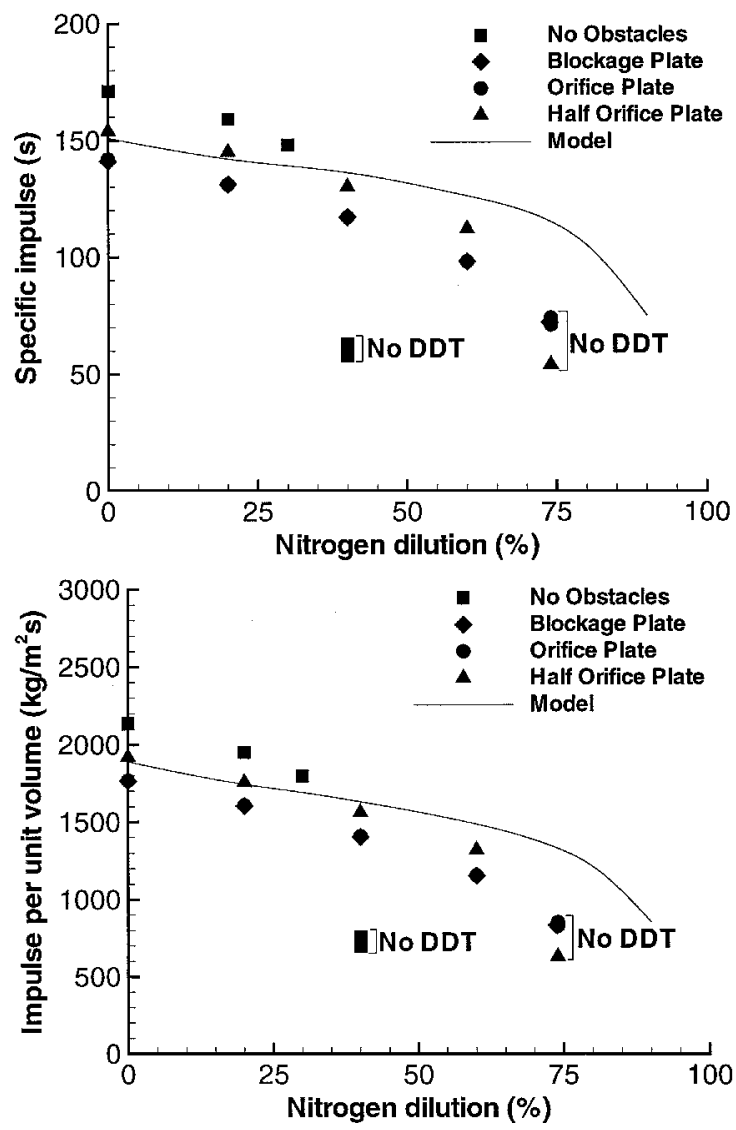

Fig. 16 Impulse measurements for stoichiometric $\mathrm{C}_{2} \mathrm{H}_{4}-\mathrm{O}_{2}$ mixtures with varying nitrogen dilution at $100-\mathrm{kPa}$ initial pressure in the 1.016-m-long tube. 
the impulse by an average of $25 \%$ from the value measured without obstacles when fast transition to a detonation occurs (Fig. 15). This impulse loss is due to additional drag from the obstacles and added heat transfer to the obstacles reducing the energy available for conversion into thrust.

\section{Effect of Extensions}

Proposed concepts for pulse detonation engines have often included the addition of different kinds of extensions, including nozzles, to the basic straight detonation tube. In part, this is motivated by the effectiveness of converging-diverging nozzles in conventional rocket motors. The effectiveness of a converging-diverging nozzle is based on the steady flow conversion of the thermal to kinetic energy. However, the pulse detonation engine is an unsteady device that relies on waves to convert the thermal energy into kinetic energy. It is not obvious how a nozzle would affect performance because the diffraction of the detonation wave through a nozzle is a complex process that involves significant losses.

We have approached this problem experimentally by examining the effect of various exit treatments on the measured impulse. Previous experiments by Zhdan et al. ${ }^{4}$ with straight cylindricalextensions indicate that the mixture-based specific impulse will increase as the ratio of the overall tube length, $L_{t}$, to the tube length filled with combustible gases, $L$, increases. Note that the mass of air in the extension volume is not included in the mixture mass used to compute the specific impulse. In our tests, as in Ref. 4, a thin diaphragm separates the tube length filled with the combustible mixture from the extension, which was filled with air at atmospheric conditions. This simulates the condition of having a single tube only partially filled with explosive mixture.

\section{Extensions Tested}

Three differentextensions were tested on the detonation tube with a length of $1.016 \mathrm{~m}$ in a ballistic pendulum arrangementto determine their effect on the impulse. Each extension modified the total tube length $L_{t}$, while the charge length $L$ remained constant.

The first extension was a flat plate $\left(L_{t} / L=1\right)$ or flange with an outer diameter of $0.381 \mathrm{~m}$ that extended radially in the direction perpendicular to the tube's exhaust flow. A hole located in the center of the plate matched the tube's inner diameter, thus increasing the apparent wall thickness at the exhaust end from $0.0127 \mathrm{~m}$ to $0.1524 \mathrm{~m}$. The purpose of this flange was to see if the pressure behind the diffracting shock wave would contribute significantly to the specific impulse. In effect, this examines the role of the last term (wall thickness) of Eq. (4) in the momentum control volume analysis. The second extension was a straight cylinder $\left(L_{t} / L=1.6\right)$ with a length of $0.609 \mathrm{~m}$. This extension simulated a partial fill case. The third extension was a diverging conical nozzle $\left(L_{t} / L=1.3\right)$ with a half angle of $8 \mathrm{deg}$ and a length of $0.3 \mathrm{~m}$.

\section{Impulse Measurements}

The flat plate and straight extension were tested with ethyleneoxygen-nitrogen mixtures on a tube that did not contain internal obstacles (Fig. 17).

The flat plate extension yielded a maximum specific impulse increase of $5 \%$ at $0 \%$ nitrogen dilution, which is within our uncertainty in measured impulse. This effect can be understood by recognizing that the flat plate or flange extension has a minimal effect on the impulse because the shock Mach number decays very quickly as the shock diffracts out from the open end. The amount of impulse contributed by the pressure of the decaying shock is relatively small compared to that obtained from the pressure of the detonation products on the thrust surface at the closed end of the tube. In addition, the rate of pressure decrease at the exit is relatively unaffected by the flange so that the rate of pressure decay at the thrust surface is very similar with and without the flat plate. At $40 \%$ nitrogen dilution, DDT did not occur, and the flat plate extension decreased the impulse by $7 \%$. This percentage decrease is within the experimental uncertainty for cases with late or no DDT, which prevents any conclusion about the plate's performance for this test case.
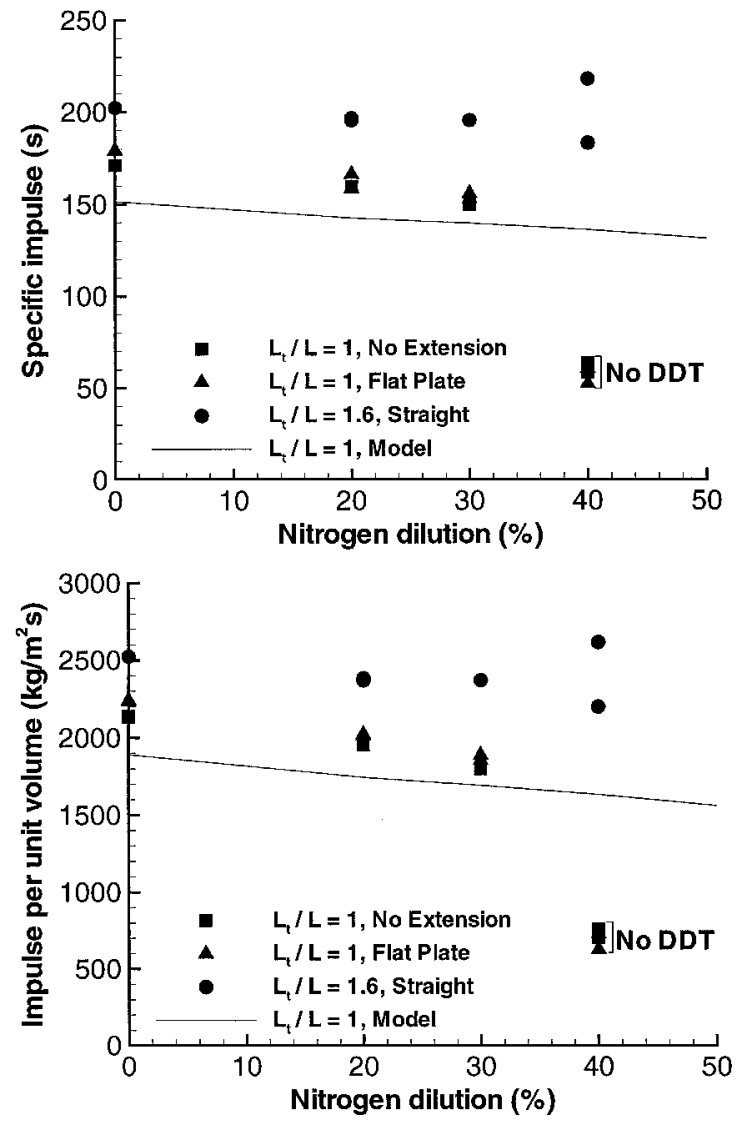

Fig. 17 Specific impulse for stoichiometric $\mathrm{C}_{2} \mathrm{H}_{4}-\mathrm{O}_{2}$ mixtures at $100-\mathrm{kPa}$ initial pressure with varying diluent and no internal obstacles.

The straightextensionincreased the measured specific impulse by $18 \%$ at $0 \%$ nitrogen dilution, whereas a $230 \%$ increase in the specific impulse was observed at $40 \%$ nitrogen dilution. This large increase in the specific impulse occurred because the additional tube length enabled DDT to occur in the extension's confined volume.

To better isolate the effect of the extensions over the range of diluent percentages tested, cases of late or no DDT were eliminated by the addition of the half orifice plate obstacles (Fig. 6). Both the straight extension and diverging nozzles were tested as a function of diluent amount (Fig. 18). The flat plate extension was not retested due to its small effect on the measured impulse shown earlier. The straight extension attached to a tube with internal obstacles increased the specific impulse by an average of $13 \%$. As already shown, the straight extension attached to a tube without internal obstacles increased the impulse by $18 \%$. This $5 \%$ reduction in impulse is due to drag and heat transfer losses induced by the obstacles. The diverging nozzle had a minor effect, increasing the specific impulse by an average of $1 \%$, which is within the experimental uncertainty.

The straight extension was more effective than the diverging nozzle in increasing impulse (Fig. 18). One explanation ${ }^{5,18}$ of this effect is that the additional length of the straight extension as compared with the diverging extensiondelays the arrival of the expansion wave from the tube exit, effectively increasing the pressure relaxationtime and the impulse. Standard gasdynamics considerations indicate that two reflected waves will be created when an extension filled with inert gas is added to a detonation tube. The first wave is due to the interaction of the detonation with the mixture-air interface and is much weaker than the wave created by the shock or detonation diffraction at the tube exit. Additionally, the continuous area change of the diverging nozzle creates expansion waves that propagate back to the thrust surface, which results in a gradual but continuous decrease in pressure that starts as soon as the detonation reaches the entrance to the diverging nozzle. Another way to interpret these impulse results with added extensions is that the added inert gas 

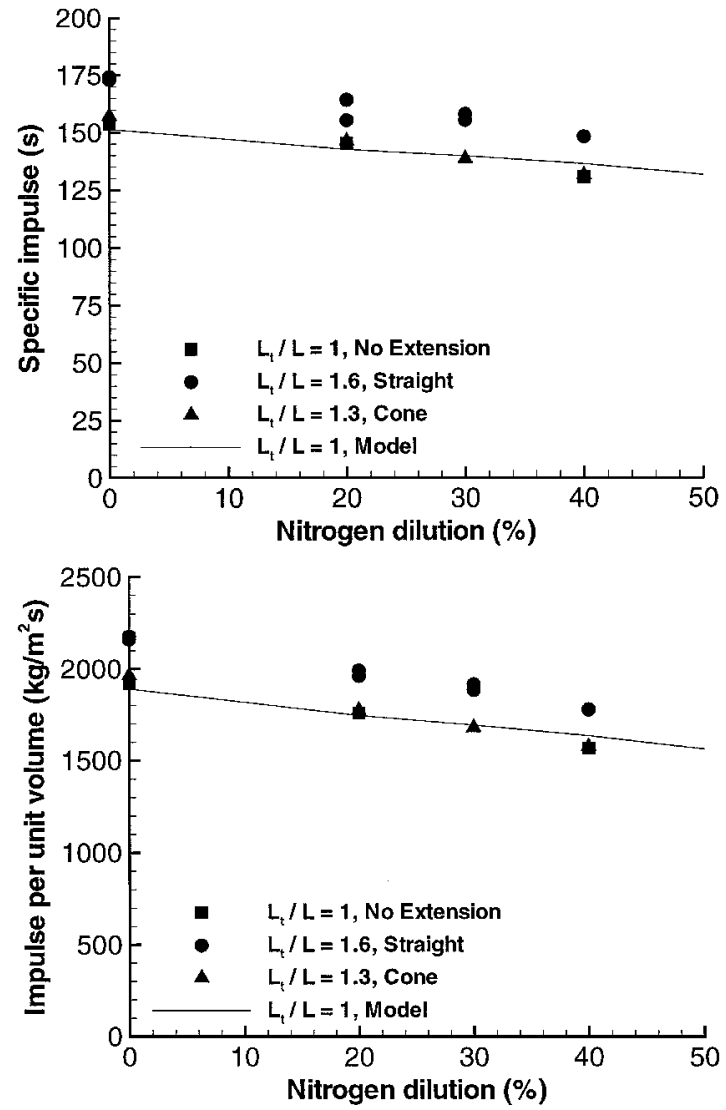

Fig. 18 Specific impulse for stoichiometric $\mathrm{C}_{2} \mathrm{H}_{4}-\mathrm{O}_{2}$ mixtures at $100-\mathrm{kPa}$ initial pressure with varying diluent and half orifice plate internal obstacles.

provides additional tamping ${ }^{13}$ of the explosion, which will increase the momentum transfer from the detonation products to the tube.

\section{Summary}

Single-cycle impulse measurements were made for deflagrations and detonations initiated with a $30-\mathrm{mJ}$ spark in three tubes of different lengths and inner diameters. A ballistic pendulum arrangement was used, and the measured impulse values were compared to those obtained from an analytical model. ${ }^{7}$ The measured impulse values were estimated to have an uncertainty of $\pm 6.3 \%$ in cases where DDT occurred sufficiently early within the tube. When the pressure histories measured at several locations in the tube were studied, four internal flow regimes were identified. Internal obstacles, with a constant blockage ratio of 0.43 , were used to reduce DDT times and initiate detonations in insensitive mixtures such as those with a high diluent amount. Times to transistion were measured with ionization probes. The internal obstacles were found to reduce DDT times for insensitive mixtures and even enable highly insensitive mixtures (up to $60 \%$ dilution in ethylene-oxygen mixtures) to transition. However, the effectiveness of the obstacles is limited because detonations could not be obtained in ethylene-air (75\% dilution) in the $1.016-\mathrm{m}$ tube. It was determined that those regimes in which slow or no transition to detonation occurred resulted in impulse values $30-50 \%$ lower than model $^{7}$ predictions. For cases of fast transition to detonation, the inclusion of obstacles decreased the measured impulse by an average of $25 \%$ as compared with the measured impulse for a tube without internal obstacles.

The effect of different exit arrangements was studied by using three different types of extensions. A relationship between the overall length-to-charge length $\left(L_{t} / L\right)$ ratio and impulse was observed. The straight extension, with a $L_{t} / L$ ratio of 1.6 , resulted in the greatest increase in impulse of $18 \%$ at $0 \%$ dilution and no internal obstacles. This increase in impulse is due to the increase in momentum transfer to the tube due to the additional mass contained in the extension.
The results of this experimental work have several significant implications for pulse detonation engine technology. The use of internal obstacles may be effective in initiating detonations in highly insensitive mixtures of larger cell widths such as all of the storable liquid hydrocarbonfuels. However, because there are limits to obstacle effectiveness, their use will have to be optimized for a given mixture and application. The use of extensions may also be beneficial in augmenting the specific impulse obtainable from a given fuel-oxidizer mass. However, the maximum impulse is always obtained by filling the available tube volume entirely with the combustible mixture. Additional studies are required to quantify the effect on impulse that could be obtained with diverging and converging-diverging nozzles.

\section{Acknowledgments}

This work was supported by the Office of Naval Research (ONR) Multidisciplinary University Research Initiative, Multidisciplinary Study of Pulse Detonation Engine (Grant 00014-99-1-0744, Subcontract 1686-ONR-0744), and General Electric Contract GE-PO A02 81655 under DABT-63-0-0001.

\section{References}

${ }^{1}$ Nicholls, J. A., Wilkinson, H. R., and Morrison, R. B., "Intermittent Detonation as a Thrust-Producing Mechanism," Jet Propulsion, Vol. 27, No. 5, 1957, pp. 534-541.

${ }^{2}$ Schauer, F., Stutrud, J., and Bradley, R., "Detonation Initiation Studies and Performance Results for Pulsed Detonation Engines," AIAA Paper 20011129, Jan. 2001

${ }^{3}$ Cooper, M., Jackson, S., Austin, J., Wintenberger, E., and Shepherd, J. E., "Direct Experimental Impulse Measurements for Deflagrations and Detonations," AIAA Paper 2001-3812, July 2001.

${ }^{4}$ Zhdan, S. A., Mitrofanov, V. V., and Sychev, A. I., "Reactive Impulse from the Explosion of a Gas Mixture in a Semi-infinite Space," Combustion, Explosion and Shock Waves, Vol. 30, No. 5, 1994, pp. 657-663.

${ }^{5}$ Zitoun, R., and Desbordes, D., "Propulsive Performances of Pulsed Detonations," Combustion Science Technology, Vol. 144, 1999, pp. 93 114.

${ }^{6}$ Harris, P. G., Farinaccio, R., and Stowe, R. A., "The Effect of DDT Distance on Impulse in a Detonation Tube," AIAA Paper 2001-3467, July 2001.

${ }^{7}$ Wintenberger, E., Austin, J., Cooper, M., Jackson, S., and Shepherd, J. E., "Analytical Model for the Impulse of a Single-Cycle Pulse Detonation Engine," AIAA Paper 2001-3811, July 2001.

${ }^{8}$ Kailasanath, K., "Recent Developments in the Research on Pulse Detonation Engines," AIAA Paper 2002-0470, Jan. 2002.

${ }^{9}$ Lindstedt, R. P., and Michels, H. J., "Deflagration to Detonation Transitions and Strong Deflagrations in Alkane and Alkene Air Mixtures," Combustion and Flame, Vol. 76, May 1989, pp. 169-181.

${ }^{10}$ Cooper, M., Jackson, S., and Shepherd, J. E., "Effect of Deflagrationto-Detonation Transition on Pulse Detonation Engine Impulse," Graduate Aeronautical Labs., GALCIT Rept. FM00-3, California Inst. of Technology, Pasadena, CA, July 2000.

${ }^{11}$ Bevington, P. R., Data Reduction and Error Analysis in the Physical Sciences, McGraw-Hill, New York, 1969, Chap. 4, pp. 56-65.

${ }^{12}$ Reynolds, W. C., "The Element Potential Method for Chemical Equilibrium Analysis: Implementation in the Interactive Program STANJAN, Version 3," Technical Rept., Dept. of Mechanical Engineering, Stanford Univ., Stanford, CA, Jan. 1986.

${ }^{13}$ Kennedy, J. E., "The Gurney Model of Explosive Output for Driving Metal," Explosive Effects and Applications, edited by J. A. Zuker and W. P. Walters, Springer, New York, 1998, Chap. 7, pp. 221-257.

${ }^{14}$ Shepherd, J. E., and Kaneshige, M., "Detonation Database," Graduate Aeronautical Labs., GAL CIT Rept. FM97-8, California Inst. of Technology, Pasadena, CA, July 1997, rev. 2001; also www.galcit.caltech.edu/detn_db/html May 2002.

${ }^{15}$ Dorofeev, S., Sidorov, V. P., Kuznetzov, M. S., Matsukov, I. D., and Alekseev, V. I., "Effect of Scale on the Onset of Detonations," Shock Waves, Vol. 10, No. 2, 2000, pp. 137-149.

${ }^{16}$ Dorofeev, S., Kuznetsov, M., Alekseev, V., Efimenko, A., and Breitung, W., "Evaluation of Limits for Effective Flame Acceleration in Hydrogen Mixtures," Journal of Loss Prevention in the Process Industries, Vol. 14, No. 6, 2001, pp. 583-589.

${ }^{17}$ Jones, S. A. S., and Thomas, G. O., "Pressure Hot-Wire and Laser Doppler Anemometer Studies of Flame Acceleration in Long Tubes," Combustion and Flame, Vol. 87, No. 1, 1991, pp. 21-32.

${ }^{18}$ Chiping, L., Kailasanath, K., and Patnaik, G., "A Numerical Study of Flowfield Evolution in a Pulsed Detonation Engine," AIAA Paper 20000314, Jan. 2000. 